Available online at $\quad$ http://www.jfas.info

\title{
HIGH-DENSITY LIPOPROTEIN ATTENUATES SECRETION AND GENE EXPRESSION OF CELLULAR ADHESION MOLECULES AND PROINFLAMMATORY CYTOKINES IN LIPOPOLYSACCHARIDE-STIMULATED ENDOTHELIAL CELLS
}

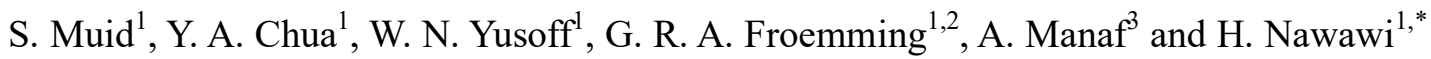 \\ ${ }^{1}$ Institute for Pathology, Laboratory and Forensic Medicine (I-PPerForM), \\ UniversitiTeknologi MARA, Selangor, Malaysia \\ ${ }^{2}$ Institute for Medical Molecular Biotechnology, Faculty of Medicine, UniversitiTeknologi \\ MARA, Selangor, Malaysia \\ ${ }^{3}$ Faculty of Agriculture and Biotechnology, Universiti Sultan ZainalAbidin, Terengganu, \\ Malaysia
}

Published online: 10 November 2017

\begin{abstract}
This study was conducted to investigate the effects of high-density lipoprotein (HDL) on secretion and gene expression of intercellular adhesion molecules-1 (ICAM-1), vascular cell adhesion molecule-1 (VCAM-1), endothelial-leukocyte adhesion molecule-1 (E-selectin), interleukin-6 (IL-6) and tumor necrosis factor alpha (TNF- $\alpha$ ) by human vascular endothelial cells (HUVEC). Lipoploysacharides-stimulated HUVEC was incubated with different concentrations of HDL (20-120 mg/dL) for 16 hours. The levels of all biomarkers were measured by ELISA. Total RNA was extracted and all bioamarkers' mRNA levels were measured by Taqman real-time polymerase chain reaction assay.
\end{abstract}

Author Correspondence, e-mail: hapizah.nawawi@gmail.com

doi: http://dx.doi.org/10.4314/jfas.v9i6s.25 
Different HDL concentrations reduced the secretion and expressonof all biomarkers except VCAM-1, which may contribute to the prevention and regression of atherosclerosis.

Keywords: HDL; adhesion molecules; cytokines; endothelial cells; lipopolysaccharides.

\section{INTRODUCTION}

Inflammation plays an important role in the pathogenesis of atherosclerosis regardless of the initial cause of the endothelial dysfunction, leading to coronary heart disease (CHD) and stroke [1-2]. There is widespread of interest in investigation of potential association of plasma inflammatory biomarkers with endothelial dysfunction and atherosclerosis [3-4]. One of the commonly accepted causes of atherosclerosis is the deposition of low-density lipoprotein (LDL) in the arterial wall. The easily-oxidized LDL activates the endothelial cells to secrete proinflammatory cytokines, which subsequently attract more leukocytes to the LDL deposition site [5]. Besides the proinflammatory cytokines such as interleukin 6 (IL-6) and tumor necrosis factor alpha (TNF- $\alpha)$, adhesion molecules expressed by the endothelial cells such as intercellular adhesion molecules-1 (ICAM-1), vascular cell adhesion molecule-1 (VCAM-1) and endothelial-leukocyte adhesion molecule-1 (E-selectin) are also involved in atherosclerosis [6]. Adhesion molecules facilitate leukocytesto bind to the surface of endothelial cells whilecytokines such as TNF- $\alpha$, upregulate cellular adhesion molecules' expression[7-8]. Besides mediating the adhesion of circulating leukocytes to endothelial cells, the adhesion molecules promote transmigration of the leukocytes into the intimal space of the blood vessel, which subsequently initiate inflammatory response and lead to atherogenesis[9]. Due to the important role played by the adhesion molecules in atherogenesis, some studies even suggested that soluble forms of adhesion molecules may serve as predictor factors for onset of myocardial infarction [10-12]. In view of such intricate relationship between the proinflammatory cytokines and adhesion molecules, suppression of both proinflammatory cytokines and adhesion molecules may serve as a potential therapeutic mechanism for CHD. Epidemiological studies have strongly suggested an inverse correlation between plasma high-density lipoprotein (HDL) and the risk of developing CHD [13]. However, the atheroprotective mechanism of HDL for CHD remains unclear. Although the most widely accepted mechanism of HDL's atheroprotective mechanism is through its role in the reverse 
cholesterol transport [14]or as an antioxidant [15], it is not yet known whether other mechanisms that unrelated to the lipid transport are involved. It is also still unclear if HDL can directly inhibit expression of adhesion molecules and cytokines. This study was aimed to elucidate the in vitro effect of HDL on the secretion and gene expression of the adhesion molecules (ICAM-1, VCAM-1 and E-selectin) and cytokines (IL-6 and TNF- $\alpha$ ). Further knowledge in the atheroprotective mechanism of HDL may strengthen its potential as a therapy target in reducing the risk of CHD.

\section{METHODOLOGY}

\subsection{HDL Isolation}

Plasma was adjusted to a density of $1.21 \mathrm{~g} / \mathrm{mL}$ by adding $1.1 \mathrm{~mL}$ of plasma to $0.3270 \mathrm{~g}$ of potassium bromide and was gently mixed by a vortex mixer. A discontinuous density gradient was made by overlaying the plasma solution $(1.1 \mathrm{~mL})$ with $2.2 \mathrm{~mL}$ of saline containing $0.1 \%$ ethylenediaminetetraacetic acid in $3.3 \mathrm{~mL}$ ultracentrifuge tubes (density $=1.006 \mathrm{~g} / \mathrm{mL}$ ). The ultracentrifuge tube was sealed and centrifuged at $100,000 \mathrm{rpm}$ at $4{ }^{\circ} \mathrm{C}$ for 40 minutes using an ultracentrifuge (Optima TLX, Beckman Coulter, Palo Alto, CA, USA). HDL fraction was placed in a nitrocellulose bag and was dialyzed at $4^{\circ} \mathrm{C}$ for 24 hours. The total protein concentration was determined by a bioanalyser (Cobas Integra 400 plus, Roche Diagnostics Limited, Rotkreuz, Switzerland).

\subsection{HUVEC Isolation, Culture and Incubation Conditions}

Human umbilical vein endothelial cells line (HUVEC) purchased from Cambrex Bio Science Walkersville, USA. HUVEC ( 1 x $10^{6}$ cells $\left./ \mathrm{mL}\right)$ were cultured in $75 \mathrm{~cm}^{2}$ flasks in Medium 199 containing $20 \%$ foetal bovine serum, 10,000U/mL penicillin/streptomycin, $100 \mathrm{mg} / \mathrm{L}$ heparin, $3 \mathrm{mmol} / \mathrm{L} \mathrm{L}$-glutamine and $15 \mathrm{mg} / \mathrm{mL}$ endothelial cell growth supplement in a humidified incubator $\left(37^{\circ} \mathrm{C}, 5 \% \quad \mathrm{CO}_{2}\right)$. The cell layers were washed twice with prewarmed phosphate-buffered saline (PBS) and coated with Roswell Park Memorial Institute-1640 (RPMI-1640) media containing $25 \mathrm{mmol} / \mathrm{L}$ 4-(2-hydroxyethyl)-1-piperazineethanesulfonic acid, $2 \mathrm{mmol} / \mathrm{L}$ glutamax-I, 10\% foetal bovine serum and antibiotics. HUVEC was stimulated with lipopolysaccharide (LPS) $(1 \mu \mathrm{g} / \mathrm{mL})$ together withdifferent concentrations of HDL $(20-120 \mathrm{mg} / \mathrm{dL})$ prior toincubation in a humidified incubator $\left(37^{\circ} \mathrm{C}, 5 \% \mathrm{CO}_{2}\right)$ for 16 hours. At 
the end of the incubation, the supernatant in the flask were collected in $15 \mathrm{~mL}$ Falcon tubes and centrifuged (1200 rpm, $5 \mathrm{~min}$ ). Three portions of supernatant from each sample were used for protein secretion assay, while the cells were used for the gene expression assay.

\subsection{Protein Secretion and Gene Expression Assays}

Enzyme-link immunosorbent assay (ELISA) (Bender MedSystem, Vienna, Austria) were utilized to measure the concentrations of soluble ICAM-1 (sICAM-1), soluble VCAM-1 (sVCAM-1), E-selectin, IL-6 and TNF- $\alpha$ in HUVEC supernatants according to the standard manufacturer's protocol. Absorbance was obtained from ELISA Microplate Reader spectrophotometer (TECAN GmbH, Salzberg, Austria) at $450 \mathrm{~nm}$ wavelength. After 16 hours of stimulation, the supernatant was removed and the cells were washed twice with ice-cold PBS and trypsinised. Total RNA was extracted using RiboPureTM Kit (Ambion Inc. USA) according to the standard manufacturer's protocol. The RNA quality was assessed by a Bioanalyzer (Agilent Technologies, CA, USA).Total RNA (50 ng) was subjected to one-cycle cDNA synthesis using Sensiscript RT Kit (Qiagen, Hilden, Germany). The expression of all the adhesion molecule and cytokine genes were analyzed using real-time polymerase chain reaction (PCR) method with Taqman probes. Glyceraldehyde 3-phosphate dehydrogenase gene was used as the standard housekeeping gene for the real-time data relative quantification. Data from the reaction were collected and analysed by a proprietary software. Quantification of gene expressions were calculated based on the $\Delta \Delta \mathrm{Ct}$ method.

\subsection{Statistical Analysis}

Results were expressed as mean $\pm \mathrm{SD}$. Analysis of variance (ANOVA) was performed to assess overall differences between the different treatments. Independent t-test was performed to compare the differences between two groups of treatments. All data were analyzed using the IBM Statistical Package for the Social Sciences (SPSS) Statistics version 22 (IBM Corp., NY, USA). Significant value was set at $\mathrm{p}<0.05$.

\section{RESULTS AND DISCUSSION}

Co-incubation of LPS-stimulated HUVEC in all tested concentrations of HDL (20-120 $\mathrm{mg} / \mathrm{dL})$ significantly decrease the secretion and expression of ICAM-1 $(\mathrm{p}<0.05)$ (Fig. 1a and 1b). Lower concentrations of HDL $(20 \mathrm{mg} / \mathrm{dL}$ for secretion assay and $40 \mu \mathrm{g} / \mathrm{dL}$ for gene 
expression assay) exhibited the highest percentage of ICAM-1 inhibition compared to positive control. The expression of VCAM-1, however, do not share the same attribute as in ICAM-1. HDL only suppress both the secretion and expression of VCAM-1 at lower concentrations (20 and $40 \mathrm{mg} / \mathrm{dL}$ ), but upregulate the secretion and expression at higher concentrations (100 and $12040 \mathrm{mg} / \mathrm{dL}$ ) (Fig. 2a and 2b). On the other hand, HDL significantly suppressed both secretion and gene expression of E-selectin in all tested concentrations with the greatest suppression of secretion at higher concentration (60-120 mg/dL) (Fig. 3a and 3b).

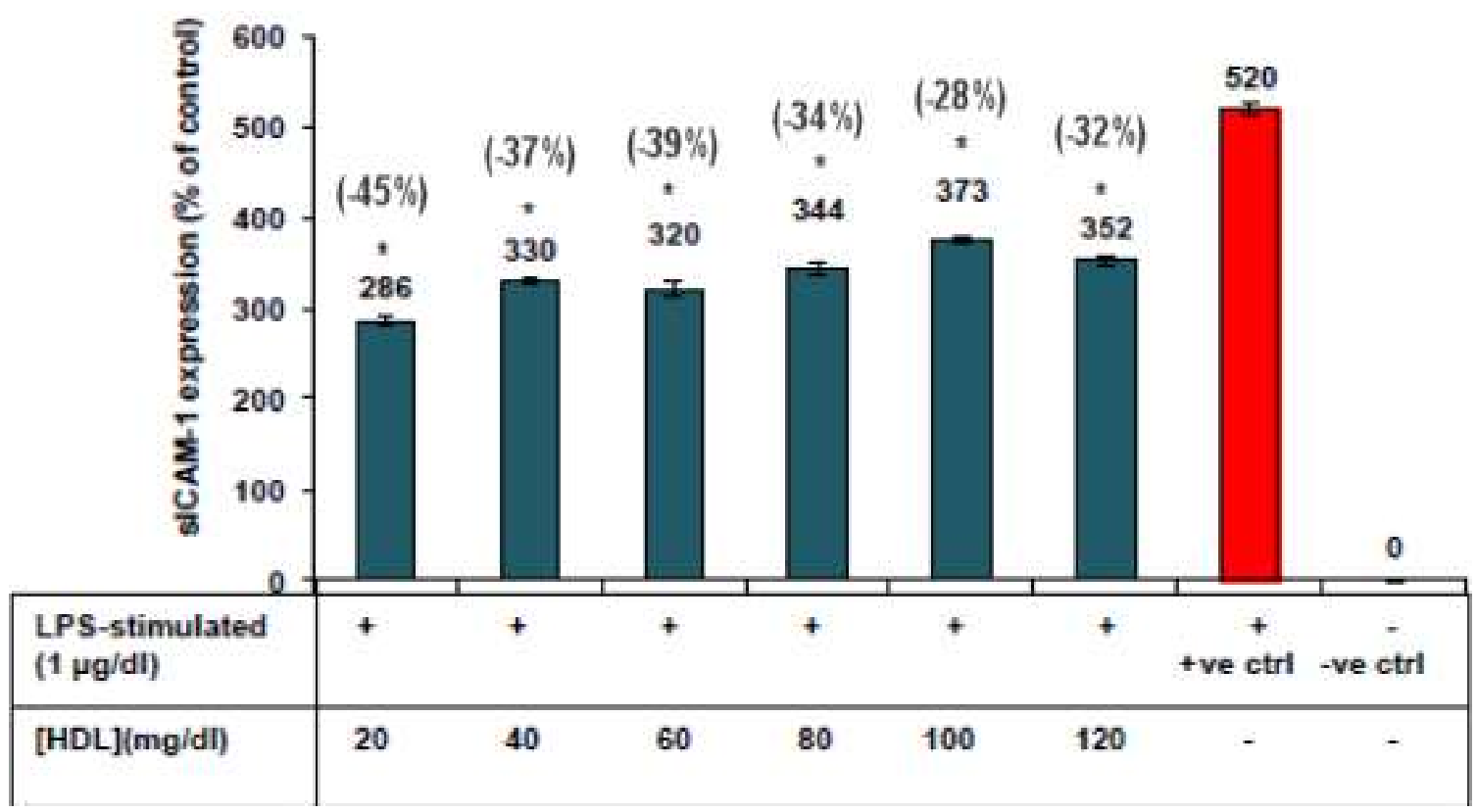

Fig.1a.Secretion of sICAM-1 by HUVECafter co-incubated with different concentrations of

HDL. HUVEC incubated with LPS alone was used as positive control. Unstimulated HUVECs without HDL was used as negative (-ve) control. Data (mean $\pm \mathrm{SD})$ are presented as $\%$ changes of sICAM-1 level in samples vs negative control. $*=p<0.05$ vs positive $(+v e)$ control. Brackets are the percentages of change vs+ve control 


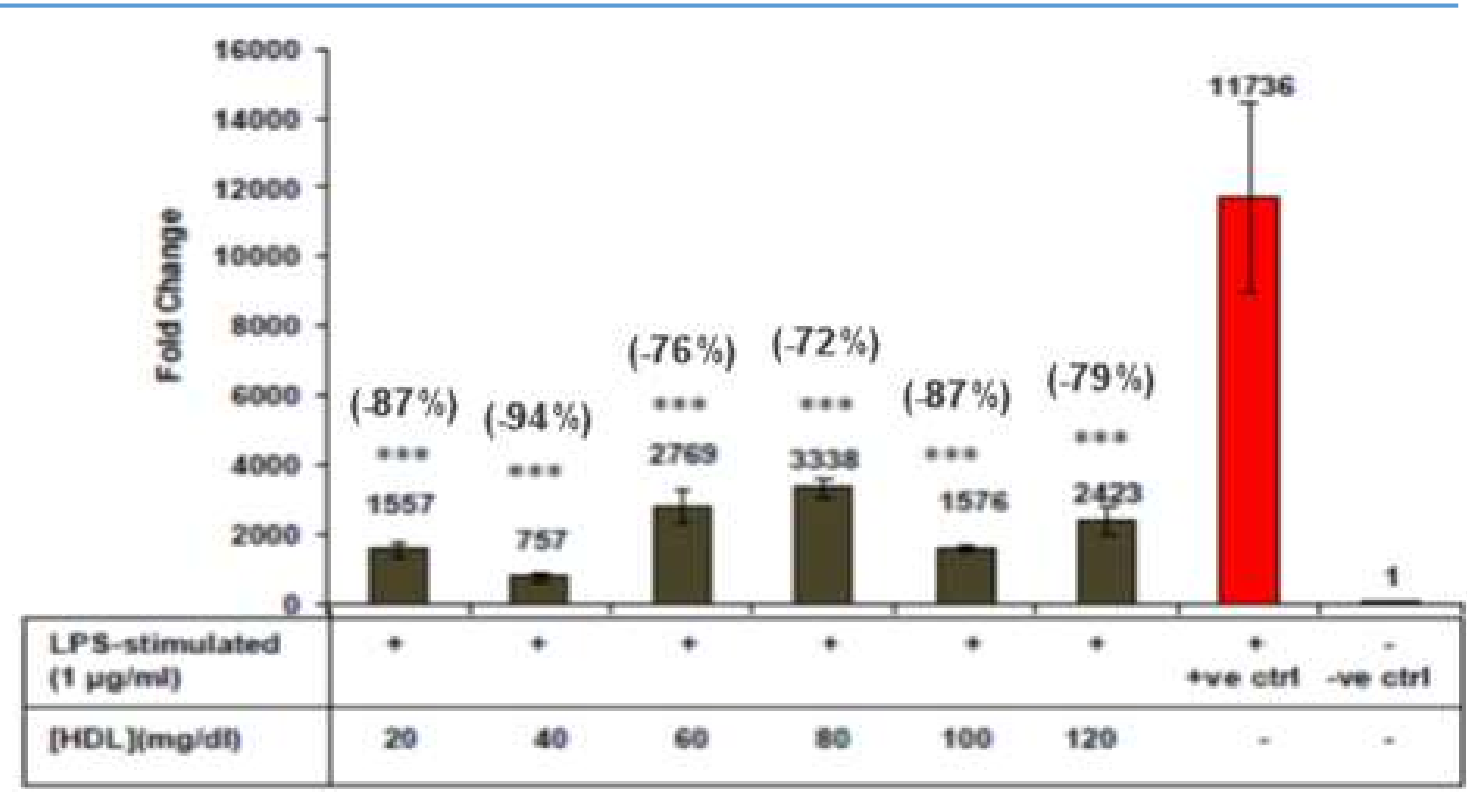

Fig.1b.Gene expression of ICAM-1 by HUVEC after co-incubated with different concentrations of HDL. HUVEC incubated with LPS alone was used as +ve control. Unstimulated HUVECs without HDL was used as -ve control. Data (mean \pm SD) are presented as fold change of ICAM-1 mRNA in samples vs-ve control. $* * *=p<0.001 \mathrm{vs}+\mathrm{ve}$ control. Brackets are the percentages of change vs+ve control

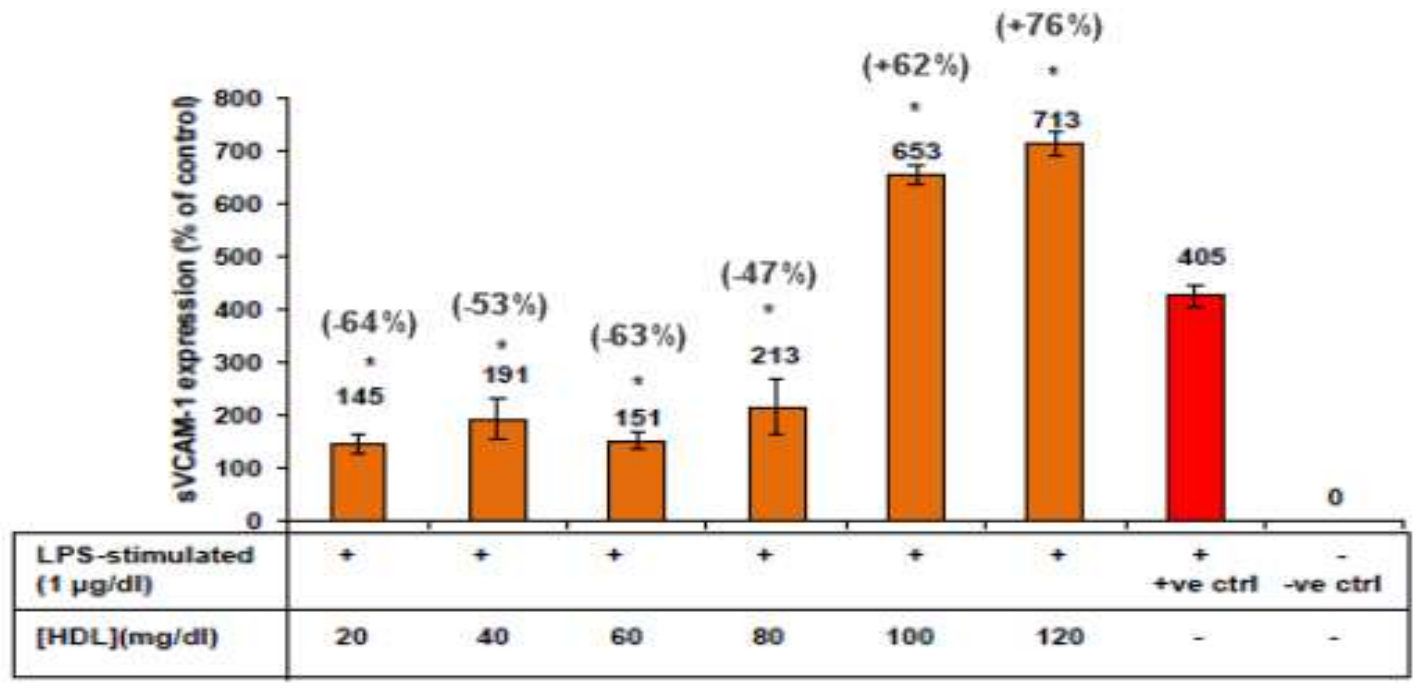

Fig.2a. Secretion of sVCAM-1 by HUVEC after co-incubated with different concentrations of HDL. HUVEC incubated with LPS alone was used as +ve control. Unstimulated HUVECs without HDL was used as -ve control. Data (mean $\pm \mathrm{SD})$ are presented as $\%$ changes of sVCAM-1 level in samples vs-ve control. $*=p<0.05$ vs + ve control. Brackets are the percentages of change vs+ve control 


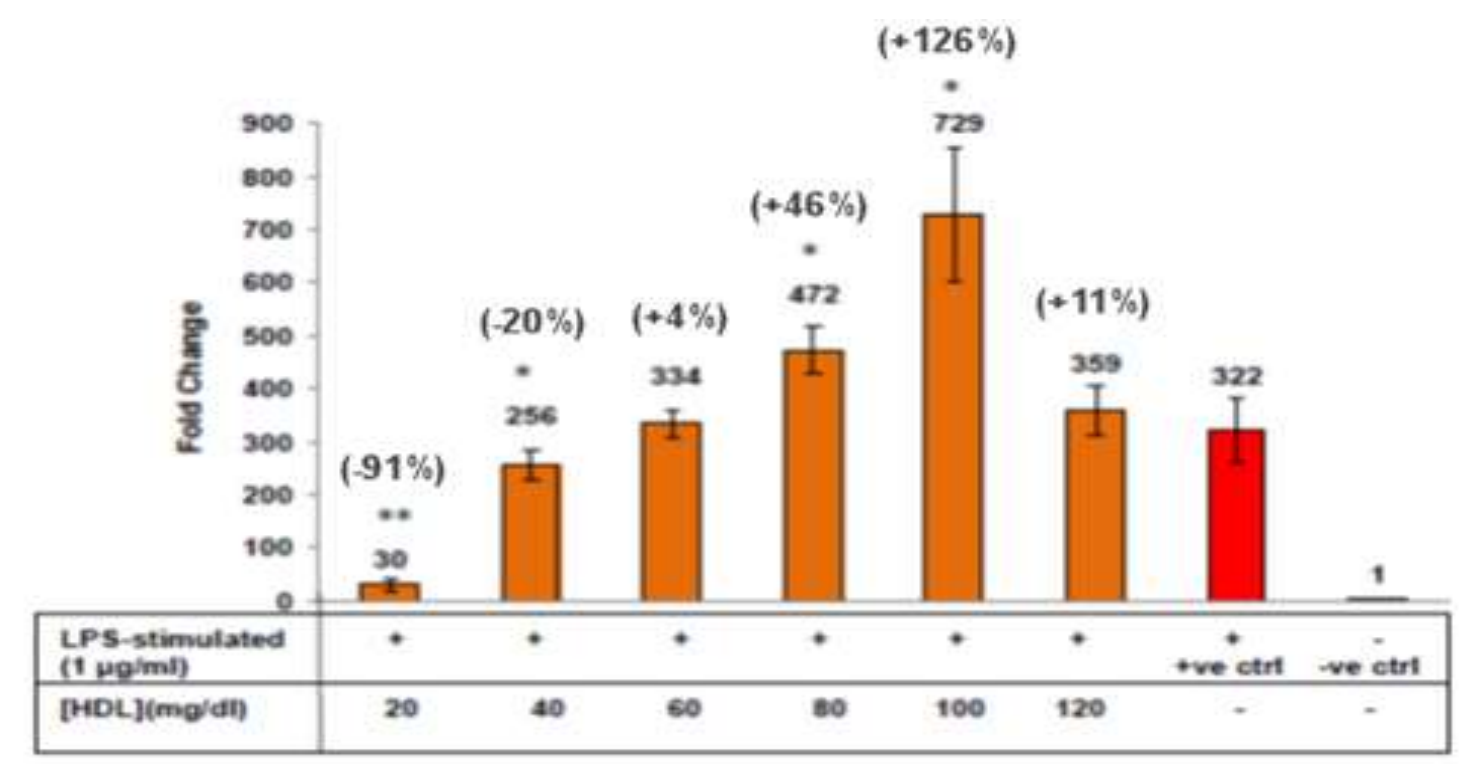

Fig.2b.Gene expression of VCAM-1 by HUVEC after co-incubated with different concentrations of HDL. HUVEC incubated with LPS alone was used as +ve control.

Unstimulated HUVECs without HDL was used as -ve control. Data (mean \pm SD) are presented as fold change of VCAM-1 mRNA in samples vs-ve control. * $* p<0.05$ compared to + ve control. $* *=p<0.01 \mathrm{vs}+\mathrm{ve}$ control. Brackets are the percentages of change vs $+\mathrm{ve}$

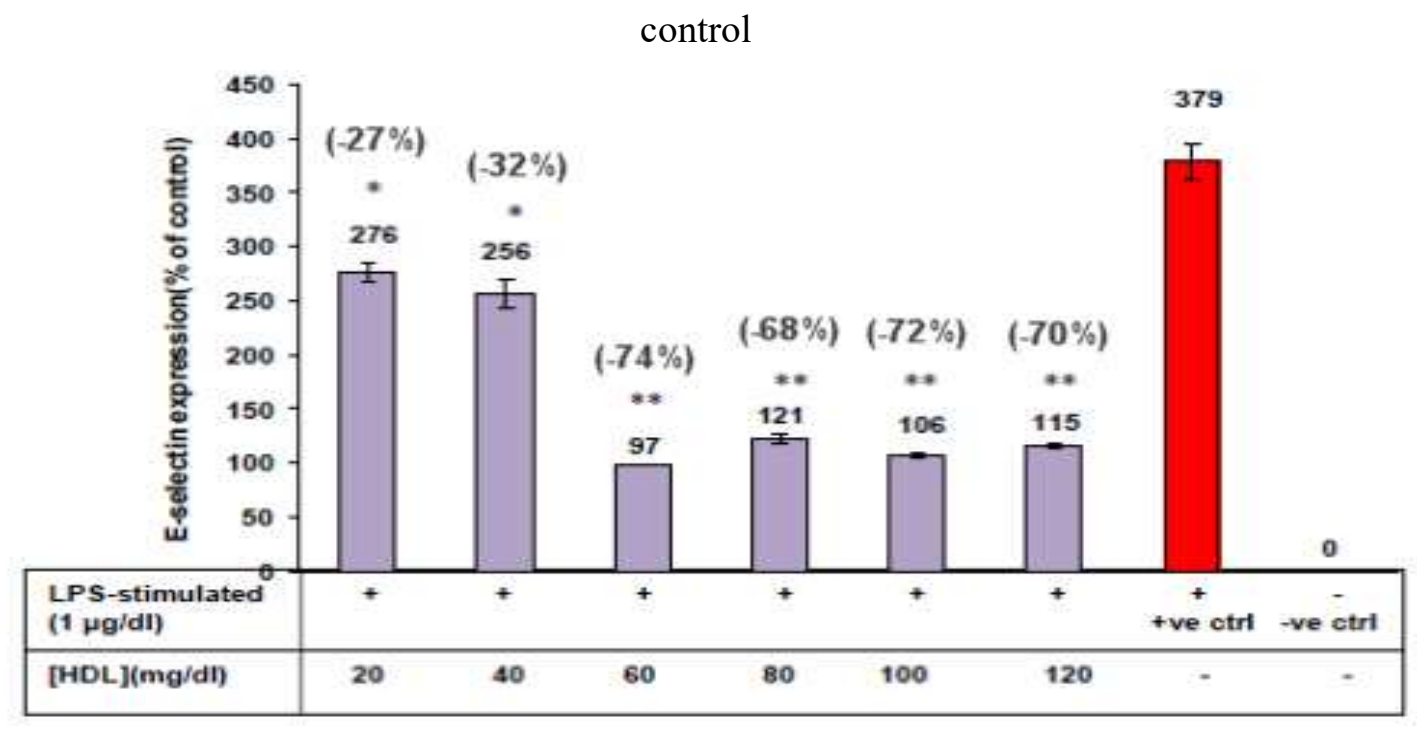

Fig.3a.Secretion of E-selectin by HUVEC after co-incubated with different concentrations of HDL. HUVEC incubated with LPS alone was used as +ve control. Unstimulated HUVECs without HDL was used as -ve control. Data (mean \pm SD) are presented as $\%$ changes of E-selectin level in samples vs-ve control. $*=p<0.05$ vs + ve control. $* *=p<0.01$ vs + ve control. Brackets are the percentages of change vs+ve control 


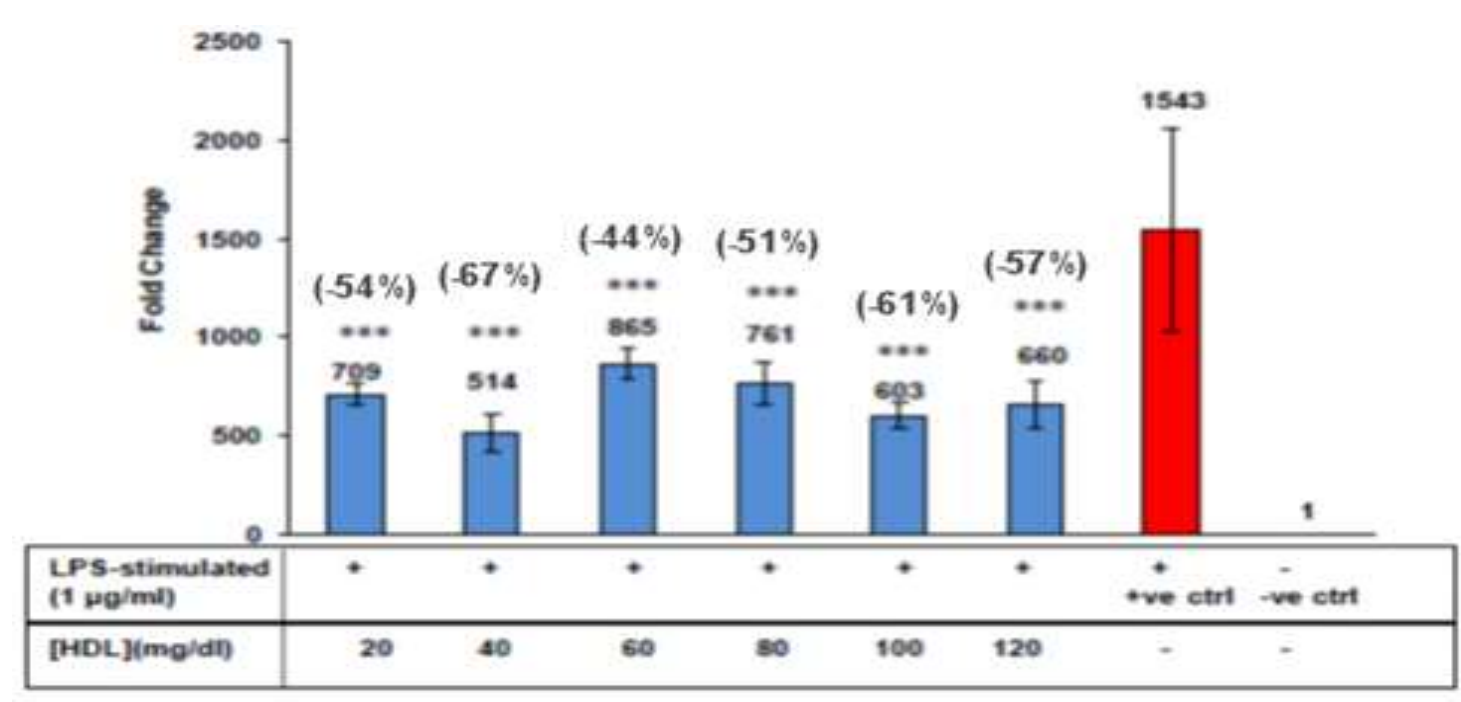

Fig.3b.Gene expression of E-selectin by HUVEC after co-incubated with different concentrations of HDL. HUVEC incubated with LPS alone was used as +ve control.

Unstimulated HUVECs without HDL was used as -ve control. Data (mean \pm SD) are presented as fold change of E-selectin mRNA in samples vs-ve control. $*=p<0.05$ compared to $+\mathrm{ve}$ control. $* *=\mathrm{p}<0.01 \mathrm{vs}+\mathrm{ve}$ control. Brackets are the percentages of change vs $+\mathrm{ve}$ control

In general, LPS-stimulated HUVEC has their IL-6's secretion and expression significantly attenuated when treated with HDL with the lowest gene expression at $60 \mathrm{mg} / \mathrm{dL}$ of HDL but gradually increased starting from 80 to $120 \mathrm{mg} / \mathrm{dL}$ of HDL, even though the expression level were still significantly lower than the positive control (Fig. $4 a$ and $4 b$ ). Similarly, TNF- $\alpha$ secretion and gene expression were not maximally suppressed at the lowest or the highest concentration of the tested HDL concentration but at the medium concentration $(80 \mathrm{mg} / \mathrm{dL})$ where the secretion and gene expression were reduced by $72 \%$ and $93 \%$ respectively when compared to positive controls (Fig. 5a and 5b). Collectively, HDL in all concentration range successfully reduced the secretion and expression of all tested adhesion molecules and proinflammatorycyotokinesby LPS-stimulated HUVEC except VCAM-1 where the secretion and gene expression were significantly increased compared to positive controls when co-incubated with high concentrations of HDL (100 and $120 \mathrm{mg} / \mathrm{dL})$, suggesting that HDL at that concentration range were proinflammatory. 


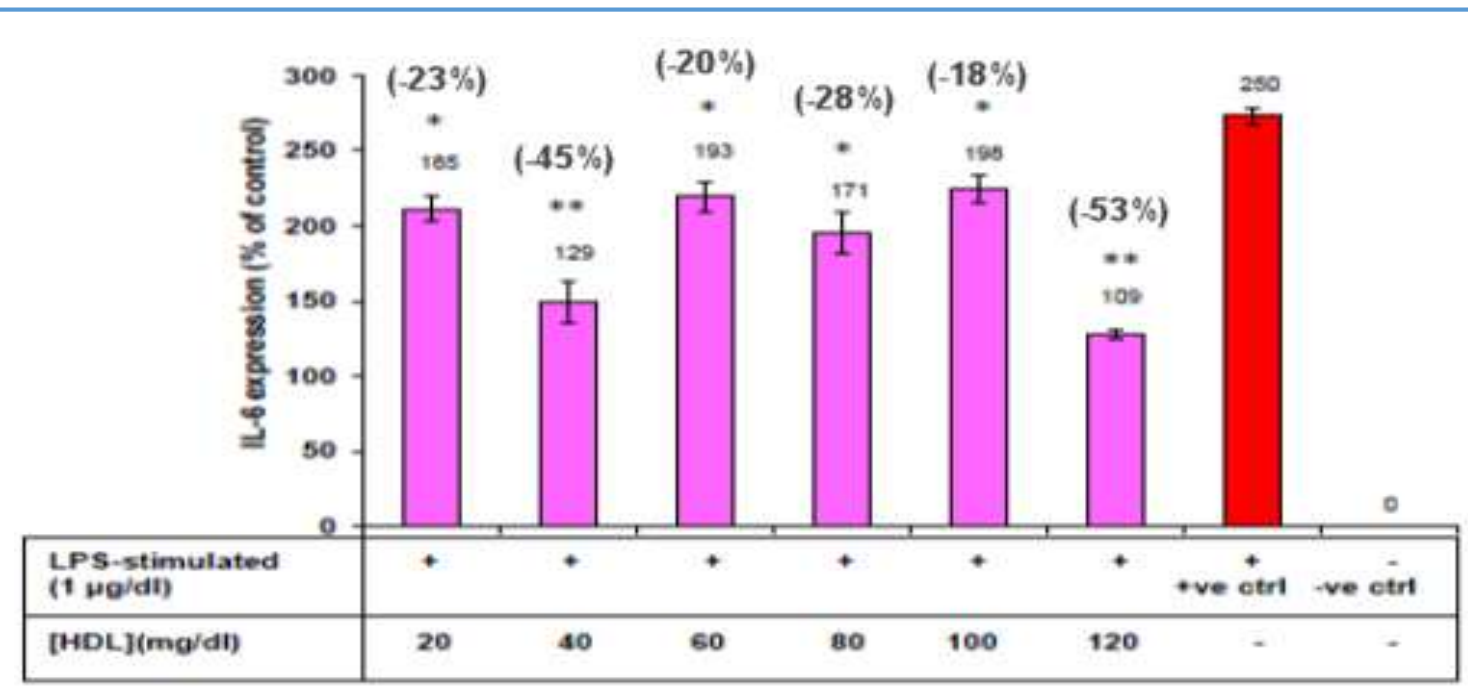

Fig.4a.Secretion of IL-6 by HUVEC after co-incubated with different concentrations of HDL. HUVEC incubated with LPS alone was used as +ve control. Unstimulated HUVECs without HDL was used as -ve control. Data (mean \pm SD) are presented as $\%$ changes of IL-6 level in samples vs-ve control. $*=\mathrm{p}<0.05 \mathrm{vs}+\mathrm{ve}$ control. $* *=\mathrm{p}<0.01 \mathrm{vs}+\mathrm{ve}$ control. Brackets are the percentages of change compared to +ve control

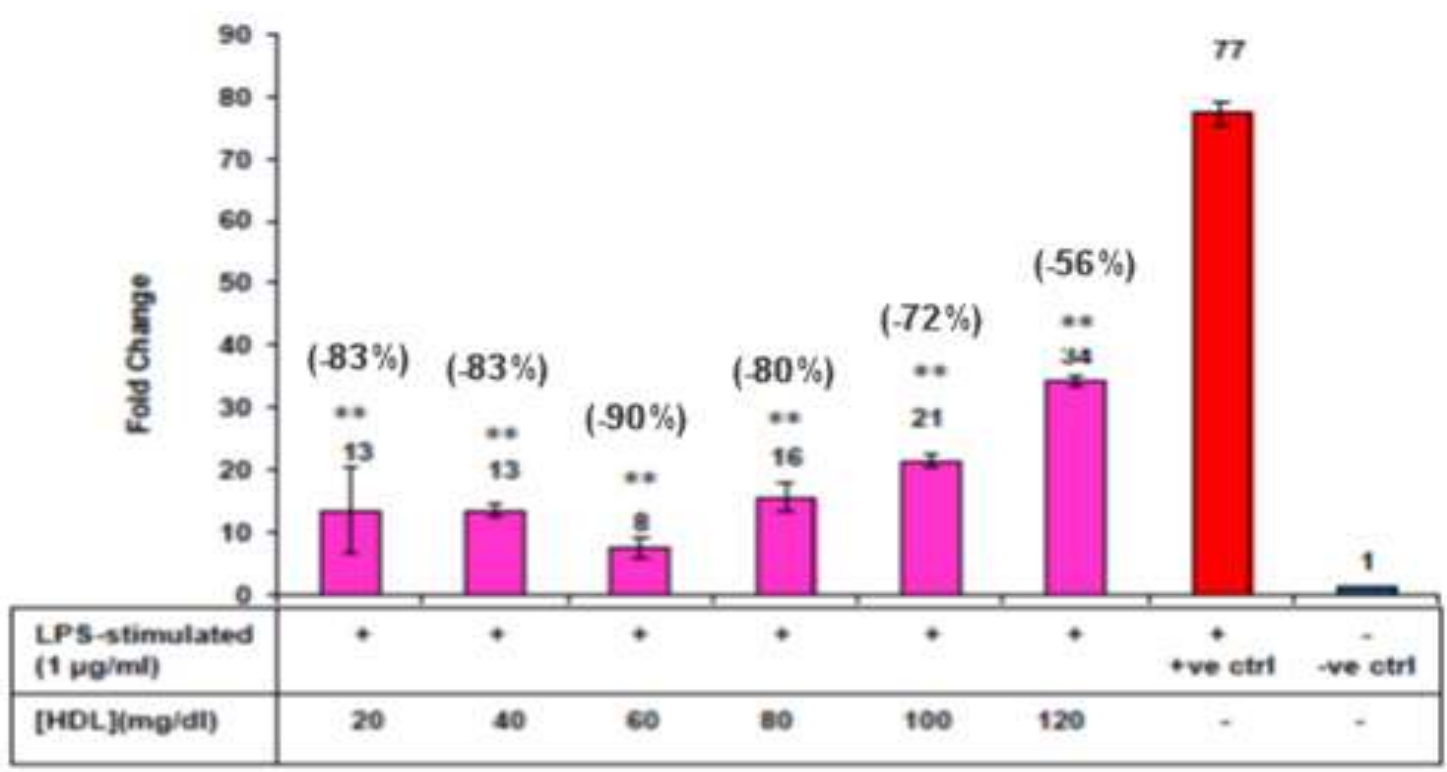

Fig.4b.Gene expression of IL-6 by HUVEC after co-incubated with different concentrations of HDL. HUVEC incubated with LPS alone was used as +ve control. Unstimulated HUVECs without HDL was used as -ve control. Data (mean \pm SD) are presented as fold change of IL-6 mRNA in samples vs-ve control. $* *=p<0.01 \mathrm{vs}+\mathrm{ve}$ control. Brackets are the percentages of change vs + ve control 


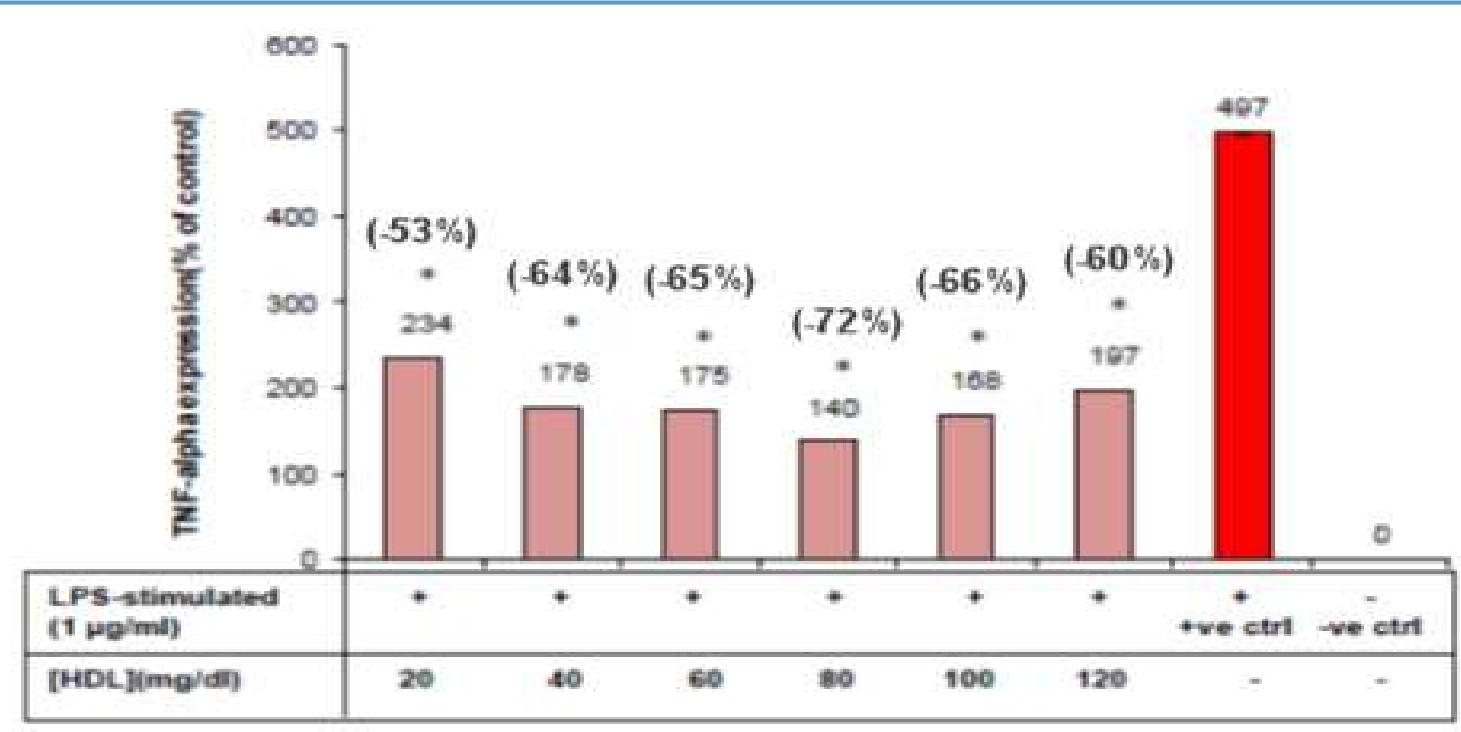

Fig.5a.Secretion of TNF- $\alpha$ by HUVEC after co-incubated with different concentrations of HDL. HUVEC incubated with LPS alone was used as +ve control. Unstimulated HUVECs without HDL was used as -ve control. Data (mean \pm SD) are presented as \% changes of TNF- $\alpha$ level in samples vs-ve control. $*=p<0.05$ vs + ve control. Brackets are the percentages of change vs +ve control

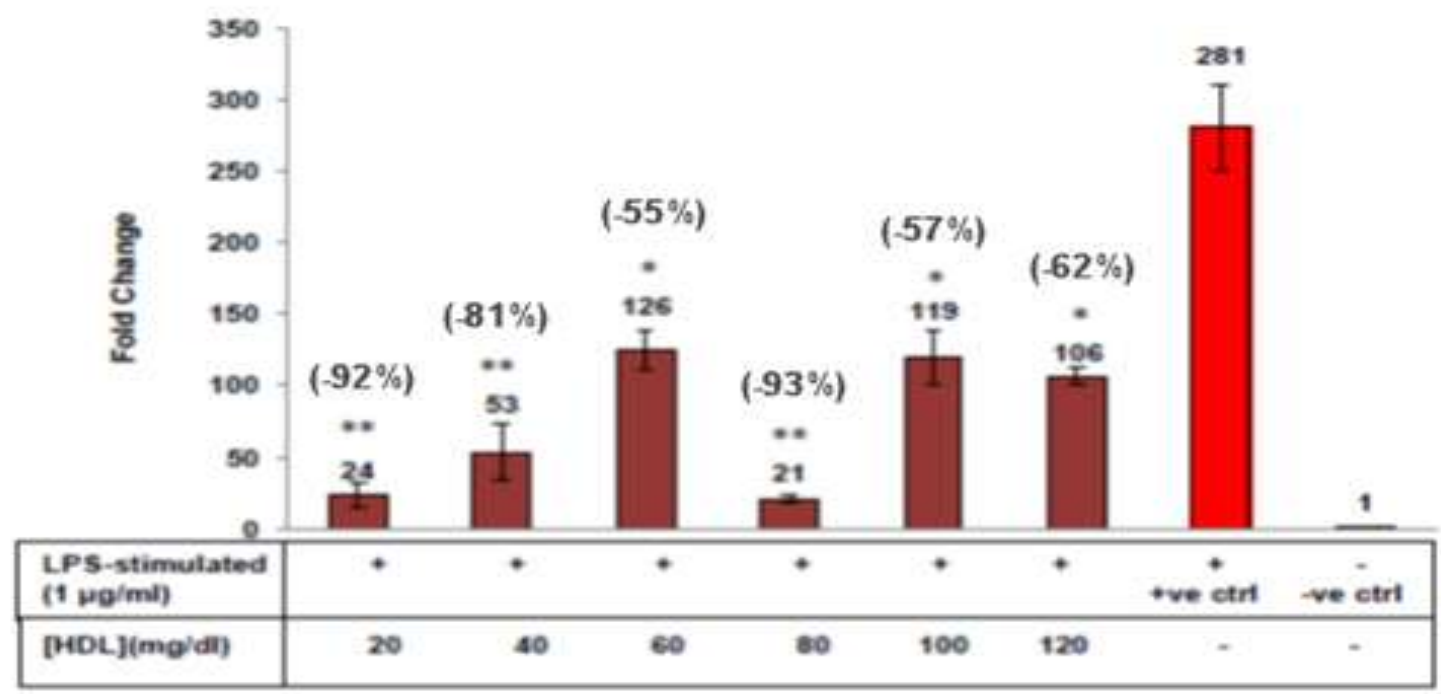

Fig.5b.Gene expression of TNF- $\alpha$ by HUVEC after co-incubated with different concentrations of HDL. HUVEC incubated with LPS alone was used as +ve control. Unstimulated HUVECs without HDL was used as -ve control. Data (mean \pm SD) are presented as fold change of TNF- $\alpha$ mRNA in samples vs-ve control. $*=p<0.05$ vs + ve control. $* *=p<0.01 \mathrm{vs}+\mathrm{ve}$ control. Brackets are the percentages of change compared to $+\mathrm{ve}$ control Atherogenesis is a complex process that involved stimulation of endothelial cells by 
pathogenic stimuli to produce proinflammatory cytokines that attract leukocytes, which in turn produce more cytokines to attract even more leukocytes to the inflammation site. An early study has utilised flow cytometry and northern blot analysisto investigate the expression of adhesion molecules by HDL-treated endothelial cells. TNF- $\alpha$ was directly introduced into the cendothelial cellscultures in order to stimulate the expression of the adhesion molecules [16]. To study the atheroprotective effects of HDL in the complex inflammation process, however, the expression of the pro-inflammatory cytokines must be investigated too. In this study, the IL- 6 and and TNF- $\alpha$ were expressed in situ by addition of LPS into the endothelial cell cultures. The downregulating effect of HDL on adhesion molecules was quantitatively measured and was found to yield similar inhibitory effect on E-selectin (in physiological level of HDL, $1 \mathrm{mg} / \mathrm{mL}$ ) with the earlier study. However, the inhibitory effects of HDL on ICAM-1 protein secretion was not as substantial as in the earlier study $(28.0 \%$ reduction vs $64.8 \%$ reduction by [16]). Instead, addition of HDL on LPS-stimulated endothelial cell culture upregulated the secretion of VCAM-1 compared to positive control.

The expected dose-dependent inhibitory effects of HDL on the secretion and gene expression of adhesion molecules and proinflammatory cytokines were also hardly observable in this study. This may partly due to the direct pathological effect of LPS on other inflammatory biomarkers not tested in this study. Nuclear factor kappa-light-chain-enhancer of activated B cells $(\mathrm{NF}-\mathrm{\kappa B})$, a transcription factor that regulates inflammatory response is also susceptible to activation by LPS. Activation of NF- $\kappa$ Bis known to upregulate a number of immunity and pro-inflammatory biomarkers, including the adhesion molecules [17]. Thus, in this study, $\mathrm{NF}-\kappa \mathrm{B}$ may had attenuated the inhibitory effect of HDL on the secretion and expression of the adhesion molecules. Interestingly, an in vitro study to investigate the effects of HDL on human coronary artery endothelial cell conducted by [18] also failed to reproduce the dose-dependent inhibitory effect of HDL on adhesion molecules as conducted by other contemporary investigators $[16,19]$. They postulated that the excessive dose of heparin used by other investigator groups in cell cultures can be the reason why the adhesion molecules were downregulated as the heparin had been demonstrated in other study group to downregulate the expression of ICAM-1 independent to the level of cytokines [20]. However, in [18] did not explain how the inhibition of adhesion molecules by HDL in other studies was 
in dose-dependent manner if the inhibition was not related to the HDL at all as they speculated. Nevertheless, this study still successfully advocates that the HDL is beneficial in providing anti-inflammatory effect even in lower-than-physiological concentration.

There were early prospective cohort-based studies that found a strong negative correlation between the level of pro-inflammatory biomarkers, especially IL-6 with HDL level [21-22]. An in vitro study that investigated the effect of different concentrations of HDL on IL-6 level secreted by HUVEC also found that HDL at $\geq 1.0 \mathrm{mg} / \mathrm{mL}$ significantly attenuated the secretion of IL-6 [23]. The inhibition effects of HDL were claimed to be similar regardless the HUVEC was stimulated by TNF- $\alpha$ or LPS. In this study, the dose-dependent inhibitory effect of HDL on the secretion of IL-6 is not observable.But, the most significant inhibition occurred at $120 \mathrm{mg} / \mathrm{dL}$ (equivalent to $1.2 \mathrm{mg} / \mathrm{mL}$ ) which is not too far off from the previous study. Inconsistent or higher than expected level of proinflammatory biomarkers can be due to the cytotoxin derived from cell culture or HDL preparation. To ensure that the observed inhibitory effect of HDL was not a false positive observation due to cytotoxic effects, prior cytotoxicity and viability assays were performed. These assays showed that the cell viability was unaffected by HDL preparations across the HDL concentrations used. Therefore, the anti-atherogenic properties of HDL which is unrelated to reverse cholesterol transport and antioxidation were successfully demonstrated in this study.Future studies especially animal studymust be conducted in order to investigate and confirm the paradox increase of secretion and gene expression of VCAM-1 even when the HDL was at physiological concentration.

\section{CONCLUSION}

HDL inhibits LPS-induced protein secretion and gene expression of ICAM-1, VCAM-1, E-selectin, IL-6 and TNF- $\alpha$ by HUVEC even when the HDL concentration is lower than its physiological concentration. The unexpected upregulation and inconsistent trend of inhibition of these proinflammatory biomarkers were probably contributed by the activation of other biomarkers that were not beinginvestigated in this study. Hence, HDL has potential benefitsin ameliorating inflammation, beyond and above its antioxidant effects or reverse cholesterol transport mechanism, in the prevention and regression of atherosclerosis. 


\section{ACKNOWLEDGEMENTS}

This study was supported by Scientific Advancement Grant Allocation (41017/401003050002)from the Academy of Sciences Malaysia.

\section{REFERENCES}

[1] Tuttolomondo A, Pecoraro R, Di Raimondo D, Di Sciacca R, Canino B, Arnao V, Buttà C, Della Corte V, Maida C, Licata G. Immune-inflammatory markers and arterial stiffness indexes in subjects with acute ischemic stroke with and without metabolic syndrome. Diabetology andMetabolic Syndrome, 2014, 6(1):1-10

[2] Dziedzic T. Systemic inflammation as a therapeutic target in acute ischemic stroke. Expert Review of Neurotherapeutics, 2015, 15(5):523-531

[3] Mudau M, Genis A, Lochner A, Strijdom H. Endothelial dysfunction: the early predictor of atherosclerosis: Review article. Cardiovascular Journal of Africa, 2012, 23(4):222-231

[4] Teixeira BC, Lopes AL, Macedo RCO, Correa CS, Ramis TR, Ribeiro J L, Reischak-Oliveira A. Inflammatory markers, endothelial function and cardiovascular risk. Jornal Vascular Brasileiro, 2014, 13(2):108-115

[5] Linton M.F., Yancey P.G., Davies S.S., Vickers K.C., Jerome W.G.J., Linton E. F. The role of lipids and lipoproteins in atherosclerosis.Massachusetts: MDText.com Inc., 2015

[6] Hwang S J, Ballantyne CM, Sharrett AR, Smith LC, Davis CE, Gotto A M, Boerwinkle E. Circulating adhesion molecules VCAM-1, ICAM-1, and E-selectin in carotid atherosclerosis and incident coronary heart disease cases. Circulation, 1997, 96(12):4219-4225

[7] Shong M, Ro HK, Kim YK, Yoo CJ, Lee JH, Song CU, Cho B Y. The cytokines, interleukin-1 beta, interleukin-6 and interferon-gamma upregulate the expression of intercellular adhesion molecule-1 (ICAM-1) in rat thyroid cell line, FRTL-5. Korean Journal of Internal Medicine, 1994, 9(2):88-92

[8] Balkwill F, Mantovani A. Inflammation and cancer: Back to Virchow? The Lancet, 2001, 357(9255):539-545

[9] Langer H F, Chavakis T. Leukocyte-endothelial interactions in inflammation. Journal of Cellular and Molecular Medicine, 2009, 13(7):1211-1220

[10] Blankenberg S, Barbaux S, Tiret L. Adhesion molecules and atherosclerosis. 
Atherosclerosis, 2003, 170(2):191-203

[11] Tzoulaki I, Murray GD, Lee AJ, Rumley A, Lowe GD, Fowkes FG R. C-reactive protein, interleukin-6, and soluble adhesion molecules as predictors of progressive peripheral atherosclerosis in the general population, Circulation, 2005, 112(7):976-983

[12] Ridker PM, Hennekens CH, Roitman-Johnson B, Stampfer M J, Allen J. Plasma concentration of soluble intercellular adhesion molecule 1 and risks of future myocardial infarction in apparently healthy men. The Lancet, 1998, 351(9096):88-92

[13] Rader DJ, Hovingh G K. HDL and cardiovascular disease. The Lancet, 2014, 384(9943):618-625

[14] Annema W, Tietge U J. Regulation of reverse cholesterol transport-A comprehensive appraisal of available animal studies.Nutrition and Metabolism, 2012, 9(1):25

[15] Soran H, Schofield JD, Durrington PN. Antioxidant properties of HDL. Frontiers in Pharmacology, 2015, 6:1-6

[16] Cockerill G W, Rye K A, Gamble JR, Vadas MA, Barter P J. High-density lipoproteins inhibit cytokine-induced expression of endothelial cell adhesion molecules. Arteriosclerosis, Thrombosis, and Vascular Biology, 1995, 15(11):1987-1994

[17] Tak PP, Firestein G S. NF-кB: A key role in inflammatory diseases. Journal of Clinical Investigation, 2001, 107(1):7-11

[18] Stannard AK, Khan S, Graham A, Owen JS, Allen S P. Inability of plasma high-density lipoproteins to inhibit cell adhesion molecule expression in human coronary artery endothelial cells. Atherosclerosis, 2001, 154(1):31-38

[19] Ashby D T, Rye K A, Clay MA, Vadas MA, Gamble JR, Barter P J. Factors influencing the ability of HDL to inhibit expression of vascular cell adhesion molecule-1 in endothelial cells. Arteriosclerosis, Thrombosis, and Vascular Biology, 1998, 18(9):1450-1455

[20] Miller SJ, Hoggatt A, Faulk W P. Heparin regulates ICAM-1 expression in human endothelial cells: an example of non-cytokine-mediated endothelial activation. Thrombosis and Haemostasis, 1998, 80(3):481-487

[21] Zuliani G, Volpato S, Blè A, Bandinelli S, Corsi AM, Lauretani F, Paolisso G, Fellin R, Ferrucci L. High interleukin-6 plasma levels are associated with low HDL-C levels in community-dwelling older adults: The InChianti study. Atherosclerosis, 2007, 192(2):384-390 
[22] Haddy N, Sass C, Droesch S, Zaiou M, Siest G, Ponthieux A, Lambert D, Visvikis S. IL-6, TNF- $\alpha$ and atherosclerosis risk indicators in a healthy family population: The STANISLAS cohort. Atherosclerosis, 2003, 170(2):277-283

[23] Gomaraschi M, Basilico N, Sisto F, Taramelli D, Eligini S, Colli S, Sirtori C R, Franceschini G, Calabresi L. High-density lipoproteins attenuate interleukin-6 production in endothelial cells exposed to pro-inflammatory stimuli. Biochimica et Biophysica Acta (BBA)-Molecular and Cell Biology of Lipids, 2005, 1736(2):136-143

\section{How to cite this article:}

Muid S, Yusoff WN, Chua YA, Froemming GRA, Manaf A, and Nawawi H. High-density lipoprotein attenuates secretion and gene expression of adhesion molecules and cytokines in lipopolysaccharide-stimulated endothelial cells. J. Fundam. Appl. Sci., 2017, 9(6S), 316-330. 